\title{
Naar scholing voor opleiders in de specialistische vervolgopleidingen
}

\author{
S. Bolhuis, C.R.M.G. Fluit, R. Venekamp, P.M. Boendermaker
}

\section{Samenvatting}

Modernisering medische vervolgopleidingen: Het Kaderbesluit van het Centraal College Medische Specialismen (CCMS) over de nieuwe eisen aan de medisch-specialistische vervolgopleidingen is goedgekeurd door VWS. Om opleiders hierbij te ondersteunen is een landelijk voorstel voor scholing van opleiders opgesteld. Hieruit worden besproken: het Raamplan met uitgangspunten en eindtermen, de opzet van de scholing, het scholen van cursusleiders en de inbedding in de Onderwijs- en Opleidingsregio's (OOR's).

Uitgangspunten Raamplan: De scholing sluit aan bij de regelgeving. Het leren van de arts in opleiding tot specialist (aios) in de medische praktijk staat centraal. De scholing steunt de opleider bij de implementatie van het geleerde. Opleiden is een verantwoordelijkheid van de hele opleidingsgroep. Scholing moet worden gecertificeerd met het oog op de accreditatie.

Eindtermen Raamplan: In de opleiderscompetenties worden niveaus onderscheiden: van dagelijkse begeleiding (observeren, feedback geven, leermomenten in de praktijk benutten) en toetsing (portfoliogesprekken) tot en met de kwaliteitszorg ten aanzien van het opleiden.

Opzet scholing: De scholing kent een trapsgewijze opbouw, waarbij op termijn alle leden van opleidingsgroepen twee (al of niet aaneengesloten) cursusdagen volgen en twee tot drie opleiders per groep het volledige traject van zes dagen. Het handelen als opleider staat centraal. Daartoe kan de scholing serieel en/of concentrisch zijn opgebouwd en wordt ook collegiale intervisie geoefend. Cursusleiding: Een cursus heeft minimaal een medisch specialist en een onderwijskundige als cursusleiding. Zij ontwikkelen hun expertise door het volgen van bestaande cursussen, observeren, en het mede ontwikkelen en met meer ervaren cursusleiding uitvoeren van cursussen.

Inbedding in OOR's: Regionale werkgroepen in het kader van de Onderwijs-en Opleidingsregio's dienen de scholing van opleiders ter hand te nemen. Een landelijke ontwikkelgroep waarin uit de regio's wordt geparticipeerd kan voor coördinatie en uitwisseling zorgen. (Bolhuis S, Fluit CRMG, Venekamp R, Boendermaker PM. Naar scholing voor opleiders in de specialistische vervolgopleidingen. Tijdschrift voor Medisch Onderwijs 2005;24(2):72-77.)

\section{Modernisering van de medisch- specialistische vervolgopleidingen}

Bij het congres van de Nederlandse Vereniging voor Medisch Onderwijs in november 2004 was er grote aandacht voor nieuwe ontwikkelingen in de medisch-specialistische vervolgopleidingen. Het Centraal College Medische Specialismen (CCMS) had hierin een belangrijke bijdrage. Het CCMS stelde februari 2004 een Kaderbesluit vast waarin nieuwe eisen worden gesteld voor de erkenning van opleidingen en opleiders. ${ }^{1}$ In dit besluit zijn ook algemene competenties voor de vervolgopleidingen vastgesteld, geformuleerd in zeven competentiegebieden: medisch handelen, communicatie, samenwerking, kennis en wetenschap, maatschappelijk handelen, organisatie en professionaliteit. ${ }^{2}$ Deze dienen de basis te zijn voor het opstellen van doelmatige programma's, het observeren van de arts-assistent in de praktijk, het op adequate wijze 
feedback geven en het voeren van voortgangs- en beoordelingsgesprekken.

In een project Modernisering Specialistenopleidingen vroeg het CCMS de landelijke wetenschappelijke verenigingen, die verantwoordelijk zijn voor de inhoud van de vervolgopleidingen, op drie punten om actie. De eerste actie betrof het aanvullen van de algemene competenties met specialisme-gebonden competenties en het op basis van de competentiegebieden inrichten van het eigen opleidingsprogramma. Het tweede punt betrof de ontwikkeling van voortgangstoetsen om regelmatig de kennis van de arts-assistenten vast te stellen. De derde actie betrof het invoeren van een systematiek van korte klinische beoordelingen (KKB), halfjaarlijkse voortgangsgesprekken en het gebruik van het portfolio bij de voortgangsgesprekken en de beoordeling. Inmiddels heeft de Minister van Volksgezondheid, Welzijn en Sport het Kaderbesluit en de bijhorende 27 opleidingsspecifieke besluiten half december goedgekeurd. ${ }^{3}$ De regelgeving geldt per 1 januari 2005. De term artsassistent is daarbij vervangen door 'arts in opleiding tot specialist' (aios).

Bij het realiseren van al deze voornemens in de praktijk spelen opleiders een cruciale rol. Aan hun competenties als opleider worden hogere en nieuwe eisen gesteld. Met het oog hierop zijn op diverse plaatsen in het land al cursussen voor opleiders ontwikkeld. Om een voor alle opleiders kwalitatief en kwantitatief voldoende aanbod te kunnen bieden, is echter meer nodig. Een werkgroep van diverse betrokkenen uit het land, bijeengebracht door de Samenwerkende Topklinische opleidingsZiekenhuizen (STZ), boog zich over dit vraagstuk. Het resultaat was een notitie Naar een Raamplan en scholing voor opleiders medische vervolgopleidingen $^{4}$ dat namens de werkgroep werd aangeboden aan zowel de STZ als de Nederlandse Federatie Universitaire ziekenhuizen
(NFU). De STZ accepteerde de notitie als basis voor beleid. Tijdens het NVMO-congres werd een rondetafeldiscussie gewijd aan het Raamplan. In onderstaande kaders worden enkele onderdelen van de notitie letterlijk weergegeven: de uitgangspunten, de te bereiken eindtermen van scholing voor opleiders, de opzet van de scholing en een traject voor het scholen van cursusleiders. De term 'arts-assistent' is vervangen door 'arts in opleiding tot specialist' (aios), omdat dit voortaan de overkoepelende term zal zijn. Tenslotte wordt ingegaan op de ontwikkeling van de Onderwijs- en Opleidingsregio's (OOR's) waarin de modernisering van de vervolgopleidingen moet worden gerealiseerd.

\section{Uitgangspunten Raamplan Scholing Opleiders}

1. De scholing sluit aan bij door het CCMS (en wetenschappelijke verenigingen) genomen besluiten en de desbetreffende documenten waarin uitspraken gedaan worden over de gewenste competenties en werkwijze van opleiders.

2. Uitgangspunt voor de invulling van de cursus is de dagelijkse praktijk waarin de opleiders en 'artsen in opleiding tot specialist' (aios) samen werken. Het leren van de aios speelt zich grotendeels af in de praktijk. Hierbij observeert de aios de opleider en de werkomgeving, krijgt uitleg, voert zelf handelingen uit en krijgt feedback. De opleider leert daarom hoe te waarborgen dat de assistent voldoende en gevarieerde leerervaringen kan opdoen, goede uitleg krijgt, relevante opdrachten krijgt, geobserveerd wordt, feedback krijgt op zijn/haar handelen en adequaatwordtbeoordeeld.Erwordenalgemene vaardigheden geoefend die voor iedere opleider relevant zijn (bijv. het geven van feedback of het voeren van een voortgangsgesprek). 
3. De scholing omvat een traject van cursusonderdelen waartussen wordt gewerkt aan de implementatie in de dagelijkse praktijk. Hiervoor wordt bewust gekozen, omdat eenmalige cursussen zelden tot structurele gedragsverandering in de praktijk leiden (d.w.z. het anders gaan opleiden en begeleiden van de aios).

4. Opleiden gebeurt door opleidingsgroepen. Op termijn zullen daarom alle opleiders (leden van opleidingsgroepen) basisexpertise moeten verwerven voor de dagelijkse praktijk van het opleiden. Minimaal twee opleiders per opleidingsgroep dienen zich - met het oog op de eindverantwoordelijkheid voor het opleidingsprogramma en de afsluitende beoordeling van aios - alle beschreven competenties eigen te maken. Overige leden van de opleidingsgroep volstaan vooralsnog met het verwerven van competenties als opleider op een basaler niveau.

5. De scholing wordt gecertificeerd door het CCMS.

\section{Eindtermen Raamplan Scholing Opleiders}

In de loop van het scholingstraject maakt de opleider zich de competenties (kennis, vaardigheden en attitude) van een goede opleider eigen en raakt gewend te reflecteren op zijn/haar functioneren in deze rol. Hij/zij is in staat om op adequate wijze:

1. in de dagelijkse praktijk feedback te geven en te ontvangen, als ook ervoor te zorgen dat anderen adequaat feedback uitwisselen;

2. het eigen rolmodel en dat van de werkomgeving (bijv. wat zijn de werkprocedures, hoe gaat men hier met elkaar om) te expliciteren en waar nodig tot onderwerp van kritische discussie te maken;
3. werkactiviteiten op de polikliniek en afdeling in te richten en te benutten als leermoment, bijv. bedside teaching, ochtendrapport, papieren visite, ontslagbrief;

4. korte klinische beoordelingen (KKB) te geven; naast $\mathrm{KKB}$ diverse andere beoordelingsinstrumenten (videofeedback, portfoliogesprekken) toe te passen en daarbij waar gepast ook andere zorgverleners in te schakelen (verpleging, e.d.);

5. vaardigheden te onderwijzen;

6. kleinschalig groepsonderwijs in te richten en uit te voeren;

7. voortgangsgesprekken te voeren die zijn voorbereid met behulp van het eigen portfolio;

8. mede invulling te geven aan de gezamenlijke verantwoordelijkheid van de opleidingsgroep en in overeenstemming daarmee de opleidingsactiviteiten een structurele plaats in de eigen werkzaamheden te geven;

9. te participeren in de kwaliteitszorg ten aanzien van het opleiden.

\section{Globale opzet van de scholing voor opleiders medische vervolg-opleidingen}

Het scholingstraject heeft een trapsgewijze opbouw. Het ideaal is dat op termijn alle leden van opleidingsgroepen het basistraject van twee cursusdagen volgen, sommige daarna nog eens twee cursusdagen volgen en twee of drie opleiders per groep het volledige traject van zes dagen doen.

\section{Opzet van de scholing voor opleiders}

1. Het volledige scholingstraject beslaat zes dagen cursorisch onderwijs, verspreid over twee tot drie jaar aangeboden. De spreiding geeft opleiders de mogelijkheid om in de tussenliggende periodes te werken aan de implementatie van het geleerde in de 
dagelijkse praktijk. Ter ondersteuning daarvan wordt in de cursus ook collegiale intervisie geïntroduceerd (zie punt 6). Het basistraject bestaat uit de eerste twee dagen.

2. Decursuswordtvoorbereidenuitgevoerd door minimaal twee cursusleiders waarbij een van de cursusleiders een medisch specialist is, die in de praktijk werkzaam is (of recent was). De andere cursusleider is geschoold op educatief gebied (d.w.z. op het gebied van leren van volwassenen, met name leren op de werkplek, onderwijskundige principes en/of organisatieverandering).

3. Tijdens de bijeenkomsten staat het oefenen van het handelen als opleider in allerlei onderwijssituaties en het reflecteren op eigen ervaringen centraal.

4. Deinhoudvandecursusdagenkanserieel en/of concentrisch worden ingedeeld: door de te verwerven competenties serieel aan bod te laten komen (waarbij een deel van de competenties dus in het eerste jaar wordt verworven, een volgend deel in het tweede en het laatste deel in het derde jaar van het traject), door concentrisch te werk te gaan (waarbij alle competenties zoveel mogelijk direct op een basaal niveau worden verworven en in volgende cursusdagen verbreed en verdiept) of door een combinatie.

5. Ter ondersteuning van het leren wordt een cd-rom aangeboden waarop o.a. voorbeelden van onderwijs in de praktijk te zien zijn, informatie over veel gebruikte onderwijsvormen kan worden geraadpleegd en een self-assessment kan worden uitgevoerd.

6. Tussen de bijeenkomsten werken opleiders aan eigen leerpunten door middel van intervisie (en/of supervisie of coaching). Voor het opzetten van collegiale intervisie worden een handleiding en begeleiding aangeboden.

\section{Traject voor het ontwikkelen van expertise als cursusleiding}

De komende jaren is aandacht noodzakelijk voor het werven en opleiden van cursusleiding. Het optreden als cursusleider vergt specifieke competenties. De medisch-specialistische cursusleider heeft zich allereerst de competenties van een opleider eigen gemaakt en is daarenboven in staat om de cursus waarin (aanstaande) opleiders zich scholen volgens de eindter-

\section{Traject voor cursusleiders}

- (Voorafgaand voor medisch-specialistische aspirant

(2 dagen cursus)

-cursusleiders:)

- Zich grondig verdiepen in de doelen, opzet, inhoud en achtergronden

- Observeren van cursusdagen

1 dag

- Participeren in voorbereiding en (verdere) ontwikkeling van scholing

- In een duo met een ervaren cursusleider (onderdelen van) de scholing verzorgen

- Feedbackgesprekken met collega-cursusleiders op basis van observatie en/of video-opnames

- Een tweede keer als cursusleider optreden

- Feedback en beoordeling van ervaren cursusleider(s)

2 dagen

1 dag

2 dagen

$2 \times 2$ uur $=$ halve dag

2 dagen

$2 \times 2$ uur $=$ halve dag 
men van het Raamplan scholing opleiders medische vervolgopleidingen voor te bereiden en uit te voeren. De medisch-specialistische cursusleider heeft een belangrijke inbreng in de cursus vanuit de medische praktijk, terwijl de educatief geschoolde cursusleider expert is in de didactiek van het medisch opleiden, met een sterke focus op het leren van aankomende professionals in de medische praktijk.

Bij het werven en opleiden van opleiders medische vervolgopleidingen als aspirant cursusleider zal goed gekeken moeten worden naar de 'elders verworven competenties' (eerder verworven expertise door scholing en ervaring als opleider). Educatief geschoolde aspirant cursusleiders zijn bij voorkeur al vertrouwd met medisch onderwijs en zullen deels bij de PAOG's of geneeskundeopleidingen kunnen worden gevonden dan wel aangetrokken. Waar dat niet mogelijk is zal regionaal naar andere oplossingen moeten worden gezocht.

Op termijn ziet een traject voor het ontwikkelen van expertise door aspirant cursusleiders er als volgt uit (in dagen per jaar).

\section{Inbedding van de ontwikkeling van scholing voor opleiders}

De modernisering van de medisch-specialistische vervolgopleidingen staat niet op zichzelf, maar maakt deel uit van een grotere operatie die al enkele jaren aan de gang is. Na adviezen van de KNMG en anderen over het medisch opleidingscontinuüm, ${ }^{5}$ van de Raad voor de Volksgezondheid en Zorg (RVZ) over taakherschikking in de gezondheidszorg, ${ }^{6}$ de evaluatie van de Wet op de Beroepen in de Gezondheidszorg (BIG) door ZonMw ${ }^{7}$ en het advies van de Commissie Implementatie Opleidingscontinuüm en Taakherschikking, ${ }^{8}$ werd in april 2004 de Stuurgroep Modernisering Opleidingen en Beroepsuitoefening in de Gezondheidszorg (MOBG) ingesteld. Deze heeft als eerste taak om de beroepenstructuur te moderniseren en daarbij plaats te maken voor nieuwe medische beroepen, als tweede taak om de opleidingen op de nieuwe structuur af te stemmen en als derde te zorgen voor een passende bekostiging en besturing. ${ }^{9}$ Een onderdeel van de opdracht van de stuurgroep betreft de vorming van opleidingsregio's, voortbouwend op de Onderwijs- en Opleidingsregio's (OOR's) die de UMC's met omliggende opleidingsziekenhuizen de afgelopen jaren al hebben gestart.

De voorstellen van de werkgroep in de notitie Naar een Raamplan en scholing voor opleiders medische vervolgopleidingen sluiten hier goed bij aan. De notitie stelt dat regionale samenwerking tussen alle belanghebbenden gewenst is en uitstekend zou passen in de opleidingsregio's. In dat kader op te richten regionale werkgroepen zouden tot taak moeten hebben om:

- actief te werven bij opleidingsgroepen voor deelname aan de scholing tot opleider specialistische vervolgopleidingen;

- aspirant cursusleiders te werven onder medisch specialisten;

- educatief geschoolden te rekruteren als aspirant cursusleider;

- uitwerking te geven aan de scholing voor opleiders;

- zorg te dragen voor het uitvoeren van scholing voor opleiders;

- het opleiden van cursusleiders;

- in een landelijke ontwikkelgroep te participeren.

Deze landelijke ontwikkelgroep dient als platform om de scholing van opleiders te stimuleren en grote lijnen van beleid voor te bereiden, c.q. om gezamenlijk algemene regels en richtlijnen voor scholing, certificering en opleiden van cursusleiding vast te stellen. Door landelijke coördinatie wordt voorkomen dat ieder voor zich weer het wiel uit moet vinden. De landelijke groep kan ook overstijgende activiteiten coördineren zoals de ontwikkeling van een cd-rom en van een handleiding voor collegiale intervisie. 
Het zal duidelijk zijn dat er de komende jaren veel werk aan de winkel is. Wij bepleiten om landelijk het voorgestelde Raamplan voor de scholing van opleiders in medische vervolgopleidingen als uitgangspunt te accepteren, maar daarbij pragmatisch om te gaan met de voorstellen teneinde vooral voortvarend van start te gaan.

\section{Dankbetuiging}

Met dank aan de overige leden van de STZwerkgroep: drs. J. Bustraan, dr. J.A.A.M. van Diemen-Steenvoorde, drs. T.E. Fick, N.F.M. Groenewegen (secretaris), dr. J.H. Hoekstra, dr. M.B. Lagaaij, dr. C.T.M. Plasmans, prof. dr. F. Scheele, prof. dr. A.J.J.A. Scherpbier, prof. dr. W.J. Schüdel (voorzitter), prof. dr. O.T. Terpstra, dr. J.C. de Valois, prof. dr. R.P. Zwierstra.

\section{Literatuur}

1. Centraal College Medische Specialismen. Kaderbesluit CCMS; 2004.

2. The Royal College of Physicians and Surgeans of Canada. CanMEDS 2000 [homepage op internet]. Ottawa: The Royal College of Physicians and Surgeans of Canada [geciteerd op 23 februari 2005]. Beschikbaar op: http://www.rcpsc.medical.org.

3. Staatscourant Nr. 241 (14 december 2004).
4. Bolhuis S, Fluit CRMG, Venekamp R, Boendermaker PM. Naar een raamplan en scholing voor opleiders medische vervolgopleidingen. STZ-werkgroep; 2004.

5. Meyboom-De Jong B, Schmidt Jongbloed LJ, Willemsen MC (editors). De arts van straks. Wijk bij Duurstede: Hentenaar; 2002.

6. Raad voor de Volksgezondheid en Zorg. Taakherschikking in de gezondheidszorg. Zoetermeer: RVZ; 2003.

7. ZonMw. Evaluatie Wet op de beroepen in de individuele gezondheidszorg. Den Haag: ZonMw; 2002.

8. Commissie Implementatie Opleidingscontinuüm en Taakherschikking. De zorg van morgen, flexibiliteit en samenhang. Alphen aan den Rijn: Haasbeek; 2003.

9. Stuurgroep Mondernisering Opleidingen en Beroepsuitoefening in de Gezondheidszorg (MOBG). Werkplan 2004-2005; 2004.

\section{De auteurs:}

$M w . d r . S$. Bolhuis is als onderwijskundige verbonden aan het Onderwijsinstituut van het UMC St Radboud te Nijmegen; daarnaast is zij lector bij de Fontys Lerarenopleiding Tilburg.

Mw. drs. C.R.M.G. Fluit is arts en onderwijskundige, verbonden aan het Onderwijsinstituut van het UMC St Radboud.

Drs. R. Venekamp is arts-stafmedewerker bij de afdeling Organisatie en Ontwikkeling van het het UMC Groningen. Dr. P.M. Boendermaker is huisarts-staflid aan de Huisartsopleiding van het UMC Groningen.

\section{Correspondentieadres:}

Mw. dr. S. Bolhuis, Onderwijsinstituut UMC St Radboud, Postbus 9101 (224), 6500 HB Nijmegen, tel: 0243610679, s.bolhuis@educ.umcn.nl.

\section{Summary}

Innovation of specialist training: The government has endorsed new criteria for specialist training programmes developed by the Dutch National College of Medical Specialists. A blueprint for an educational training programme for specialist trainers is being developed.

Starting points: The programme will focus on the learning of specialists-in-training in medical practice. It will help specialist trainers to implement what they have learned in the programme in practice. Specialist training is not a task of individual specialists only: the whole team of specialists must be involved. Accreditation of the new training programme is required.

Objectives: The programme will cover educational competencies, such as supervision of trainees (modelling, observation, feedback, providing an appropriate learning environment), (portfolio) assessment and monitoring the quality of the programme.

Organisation: The full educational training programme lasts six-days. All members of teams of specialists who provide specialist training will attend two course days, whereas two to three team members will attend six days. The programme focuses on the educational tasks of specialist trainers. Peer feedback sessions will be included in the programme.

Course leaders: Courses are taught by at least one medical specialist and one educationalist. Course teachers develop expertise by participating in existing courses, by observation, and by participating with more experienced course teachers in developing and teaching courses.

Regional implementation: In the Netherlands specialist training is organised by eight Educational and Training Regions around the academic hospitals. Regional working parties will implement the training programme. A national development group with representation from all regions will be responsible for programme coordination and exchange of experiences. (Bolhuis S, Fluit CRMG, Venekamp R, Boendermaker PM. Developing educational training for specialist trainers. Dutch Journal of Medical Education 2005;24(2):72-77.) 